\title{
O desafio da coordenação e seus impactos sobre a competitividade de cadeias e sistemas agroindustriais
}

\section{Maria Stella B. L. de Melo Saab ${ }^{1}$, Marcos Fava Neves², Leandro Del Grande Cláudio ${ }^{3}$}

1 FEA/USP.

2 FEARP/USP.

${ }^{3}$ FCAVZ/UNESP.

RESUMO - Este artigo pretende apresentar alguns dos conceitos de coordenação de sistemas agroindustriais (SAGs) e de competitividade entre cadeias, mais especificamente as cadeias de carnes (bovinos, suínos e aves). Em seguida, são analisados alguns exemplos recentes de diferentes formas de coordenação de SAGs e como elas afetam a competitividade entre as cadeias.

Palavras-chave: cadeias, carnes, competitividade, coordenação, sistemas agroindustriais

\section{Challenge of coordenation and its impacts on the competitiveness between chains and agribusiness systems}

\begin{abstract}
This paper intends to present some of the concepts of coordination of agribusiness systems (AGSs) and of competitiveness between chains, specifically meat chains (beef, pork and chicken meat). Then, some recent examples of different forms of coordination of AGSs are analysed and also how they affect competitiveness between the chains.
\end{abstract}

Key Words: agribusiness systems, chains, competitiveness, coordination, meats

\section{Introdução}

Tendo como origem a Escola de Administração da Universidade de Harvard, o conceito de agribusiness propõe uma visão sistêmica do funcionamento das atividades relacionadas à agropecuária. Em seu conjunto, o agribusiness é composto por vários sistemas agroindustriais associados aos principais produtos. Sistema agroindustrial (SAG) refere-se a um recorte feito em um determinado produto dentro do agribusiness ou agronegócio. Inclui todas as fases desde a produção de insumos até o consumidor final.

O SAG pode ser visto como sendo composto por seis conjuntos de atores: 1) agricultura, pecuária e pesca; 2) indústrias agroalimentares; 3 ) distribuição agrícola e alimentar; 4) comércio internacional; 5) consumidor; 6) indústria e serviços de apoio (Batalha \& Silva 2007).

As tecnologias utilizadas nas diferentes fases de um SAG podem ser adquiridas ou copiadas, e o produtor que não tem acesso a elas, por falta de recursos ou de escala, está seriamente prejudicado. Mas saber o que o consumidor deseja, saber como está mudando e levar essa informação a toda a cadeia, conseguindo coordenar a produção a fim de colocar no varejo exatamente aquilo que ele espera, vem-se tornando uma vantagem bastante importante, tanto para firmas individuais quanto para sistemas agroindustriais. Adaptá-los exige a coordenação de todo o SAG, o que implica em, constantemente, utilizar a troca de informações ao longo do sistema, a fim de:

a) identificar as mudanças;

b) internalizar a informação;

c) renegociar os contratos;

d) reestruturar a coordenação do SAG (Saab, 1999; Zylbersztajn, 1995).

Entre os órgãos de coordenação atuantes neste setor destacam-se as firmas, as cooperativas, as associações de empresas e mesmo o mercado, já que para a economia dos custos de transação, uma das bases para o estudo de coordenação de SAGs que mais tem sido utilizadas na literatura, o mercado e a firma são alternativas para se realizar as transações. Por outro lado, entre os serviços de apoio, citam-se, entre outros, o crédito, a mão-de-obra, o transporte, a energia, a comercialização e o marketing. (Favaret \& Siffert, 1998).

Trienekens et al. (2009), utilizam o termo gerenciamento da cadeia (chain management) ao discutir sobre o que 
chamamos de coordenação. E afirma que esse gerenciamento está relacionado, em termos simples, a:

a) reduzir incerteza e risco - mudanças imprevistas na oferta e demanda são uma grande fonte de ineficiências na busca, produção, marketing e logística das operações da cadeia. As crescentes preocupações sobre segurança alimentar aumentaram a necessidade de se ter rastreabilidade e oferecer garantia de qualidade ao longo de toda a cadeia alimentar;

b) economizar tempo - os mercados no mundo todo estão se tornando cada vez mais dinâmicos e os ciclos de vida dos produtos estão ficando menores, requerendo maiores flexibilidade e agilidade;

c) reduzir custos - a troca de informação confiável e rápida entre os parceiros na cadeia melhora a eficiência industrial, reduz estoques, melhora a efetividade da distribuição e elimina desperdícios;

d) aumentar a efetividade - saber o que o consumidor deseja torna possível, para todos os parceiros da cadeia, focar mais precisamente os gostos e necessidades do consumidor;

e) adicionar valor - a inovação no desenvolvimento de novos produtos e serviços permanece sendo a única fonte sustentável de vantagem competitiva que é difícil de atingir, mas também é a mais difícil de ser copiada;

f) melhorar a qualidade - a comparação de diferenças em qualidade entre as cadeias contribui com incentivos para melhorá-las.

Tomando-se como exemplo o setor de carnes no Brasil, percebe-se que existe uma considerável variedade de formas de coordenação entre seus diversos participantes, o que se traduz em sérios conflitos, como a falta de confiança entre as partes envolvidas nas transações (Jank, 1996). Esta deriva na escassez de relações duradouras entre as partes, mesmo em transações recorrentes, o que gera altos custos, como a necessidade de monitoramento e de barganha a cada nova transação. Resulta uma latente necessidade de ações conjuntas no sentido de eliminar esses conflitos e produzir resultados que possibilitem ganhos a todos os envolvidos, já que a competitividade no chamado "complexo carnes" tem sido crescente, com flagrantes desvantagens para a carne de boi, especialmente face à indústria do frango.

O Brasil é um grande produtor de carnes suínas, bovinas e de frangos e compete diretamente com outros países no mercado internacional. Sua vantagem competitiva é fruto da grande disponibilidade de terras, mão-de-obra barata, elevada oferta de insumos, acesso às tecnologias de produção, entre outros. Além da competição com outros países pelo mercado, há também a competição entre cadeias tanto no âmbito nacional como internacional.

E cada vez mais a competição migrará de uma concorrência entre firmas para uma concorrência entre sistemas produtivos mais amplos que extrapolam os limites destas mesmas firmas. Desta forma, o desafio maior no futuro não será somente gerir eficientemente aspectos internos aos agentes do sistema, mas também gerenciar e garantir o funcionamento harmonioso e sustentável do próprio sistema (Batalha \& Silva, 2007).

Tornar a cadeia agroindustrial eficiente e capaz de fornecer tais requisitos ao consumidor, ao mesmo tempo em que busca diminuir os desperdícios e perdas de insumos e alimentos ao longo das operações de processamento, depende de ações e práticas coordenadas de cada um de seus segmentos e agentes, além da correta gestão de bens de produção, serviços e informações. Nesse contexto, evidencia-se a importância de gerenciar a qualidade de maneira adequada ao longo das cadeias agroindustriais (Borrás \& Toledo, 2006).

\section{Coordenação}

De acordo com Borrás \& Toledo (2006), a maior facilidade de acesso aos mais variados tipos de informações, a crescente preocupação com a saúde e a evolução do conceito de gestão integrada da cadeia de suprimentos tem levado uma parcela cada dia maior de consumidores a demandarem alimentos que possuam as características que eles esperam, como sabor, coloração, aroma e textura adequados, assim como segurança à saúde.

É nesse contexto que está inserida a coordenação do SAG, pois para satisfazer esse consumidor é necessário um crescente gerenciamento de todos os agentes do sistema. Para isso, segundo Batalha \& Silva (2007), é fundamentalmente importante que todos os agentes que o compõem conheçam profundamente os atributos de qualidade que os consumidores buscam nos produtos e serviços disponibilizados nesse sistema.

Os mesmos autores acrescentam que a sustentabilidade do SAG, além da oferta de produtos que atendam a necessidade do consumidor, está baseada na eficiência desses mesmos, pois devem ser capazes de disponibilizar seus produtos com um nível adequado de qualidade e preço.

Pode-se constatar que há diversas formas de coordenação nos mais variados SAGs, sendo por vezes descoordenados e outras bem gerenciados. A coordenação estaria relacionada às diversas transações que ocorrem entre todos os agentes da cadeia, sendo responsável por 
sua eficácia. O SAG da carne bovina apresenta baixa coordenação, frente aos SAGs da carne suína e principalmente de frangos, sendo marcado por relações oportunistas que visam o lucro no curto prazo, tanto por parte dos frigoríficos como dos produtores.

Segundo Moraes e Macedo (2009), “A constituição de alianças estratégicas, sob diversos formatos de governança, visa ampliar a coordenação dos agentes sem demandar os custos administrativos e os investimentos que a internalização de outras etapas da cadeia produtiva, por um agente líder, exigiria."

Dentre as opções estratégicas das agroindústrias, usada principalmente pelas cadeias avícolas e suínas, estão as alianças. Uma aliança é uma associação de caráter duradouro entre fornecedores de produtos ou serviços com clientes e/ou intermediários comerciais. Pode contribuir para a melhoria da qualidade de atendimento aos clientes, bem como viabilizar a diminuição de estoques em pontos da cadeia de abastecimento, através da reposição contínua de produtos e entrega just in time na distribuição ao varejo (Alves, 1997 apud Carvalho-Rocha et al., 2001).

Um sistema de produção agroindustrial pode ser visto como uma rede de empresas que se forma, fundamentalmente, com base em alianças estratégicas internas a sua estrutura. As alianças estratégicas podem ainda ser vistas como empreendimentos de risco ao longo de uma escala que vai do processo de fusões e aquisições visando o controle total de uma cadeia (integração vertical completa) até arranjos cooperativos informais. No primeiro caso, existiria uma interdependência extremamente alta entre os vários agentes do sistema, ao passo que no segundo essa interdependência seria muito baixa (Batalha \& Silva, 2007).

\section{Cadeia da carne bovina}

Pigatto et al. (1999) relatam que existe um grande número de participantes em cada um dos elos da cadeia produtiva da carne bovina e que inexiste um grupo de produtores, frigoríficos ou distribuidores que efetivamente exerçam um papel de liderança nacional. O número de associações e entidades de classe (de produtores, de indústria e varejistas), estaduais e nacionais supera o necessário e conduz à superposição de funções. Em grande medida isso se deve aos conflitos de interesses entre os agentes. A cadeia como um todo, ou mesmo qualquer um de seus elos, carece de uma organização hegemônica que lhe represente e exerça funções de coordenação. Segundo os mesmos autores, esta ausência é uma das principais responsáveis pela perda de competitividade da cadeia.
Os frigoríficos de carne bovina se abastecem diretamente do mercado spot de animais gordos, em geral adquirindo o produto de intermediários especializados. Assim, predomina a coordenação de um agente intermediário que adquire o gado do produtor, o transporta e o vende ao frigorífico, em uma governança institucionalizada por meio de contratos informais e verbais (Jank, 1996).

Segundo Macedo (2009), nos anos recentes surgiram alguns sinais de maior coordenação vertical no setor industrial, tais como a ampliação da engorda em confinamentos próprios, a utilização de contratos de compra a termo de animais e de concessão de crédito antecipado aos produtores. A utilização de mercados futuros também cresceu por parte dos produtores e da indústria, como mecanismo para reduzir riscos de oscilações de preço.

Ao integrar-se verticalmente, uma empresa adquire maior controle da cadeia produtiva, o que lhe permite a adoção de ações voltadas à redução de custos e/ou de ação estratégica contra rivais, ou ainda de ações que visem à exploração do mercado consumidor do produto final. Por outro lado, a integração vertical desvia os esforços gerenciais da empresa de seu foco de negócios, elevando custos burocráticos e prejudicando a estrutura de incentivos característica do mercado (Batalha \& Silva, 2007).

A literatura retrata também que o setor de carnes se ressente de maior coordenação do sistema produtivo, constituído por produtores rurais, frigoríficos e o varejo. Essa falta de coordenação entre os agentes estimula ganhos de curto prazo, oriundos das oscilações do ciclo de preços, e que fazem com que o relacionamento entre os produtores rurais e a indústria frigorífica seja caracterizado por ações oportunistas (Macedo, 2009).

As alianças mercadológicas vêm sendo criadas para atender segmentos de mercado diferenciados. Para isto, são necessários mecanismos de coordenação específicos entre os diversos agentes que compõem o sistema. Esta ação visa gerar um produto com atributos da qualidade, demandado por agentes que sinalizam para trás e para frente na cadeia. Nestas relações é necessário cada vez mais uma postura cooperativa entre os agentes. Aumentam-se as especificidades dos ativos envolvidos, com o intuito de atender o consumidor, cada vez mais exigente e atento para adquirir produtos com segurança garantida (Carvalho-Rocha et al., 2001).

\section{Cadeia da carne avícola}

A partir do início dos anos 60, surge no sul do país uma avicultura integrada contratualmente. Trata-se de uma forma 
de coordenação entre o mercado (onde as empresas são completamente independentes e livres para realizarem as suas transações com quem quiserem, sem qualquer compromisso, formal ou não, de repetir a transação com o mesmo ator) e a integração vertical, que seria a posse, por um mesmo agente econômico, de diversas fases da produção.

A forma contratual permite que empresas diferentes tenham certas garantias, como o suprimento de matériaprima com as quantidades e especificações previamente determinadas, de um lado (a indústria), e a venda da sua produção, do outro lado (produtor), mas permaneçam como empresas separadas, reduzindo custos gerenciais e possibilitando focar capital e administração no seu negócio principal.

Esta estratégia de integração conduz as empresas a algumas vantagens como, por exemplo, ganho de qualidade na matéria prima, abastecimento constante, redução dos custos industriais nas operações de abate, padronização da carcaça, entre outras. Estas empresas integradoras poderiam repassar parte do custo da crise aos produtores enquanto as hierárquicas (integradas verticalmente) estariam mantendo ocioso um montante muito alto em capital fixo. Para o avicultor, algumas vantagens seriam uma maior produtividade, redução dos custos de produção e maior rentabilidade, formação de um plantel básico de reprodutores de alto valor zootécnico, e principalmente garantia de comercialização da produção com consequente diminuição de seu risco (Castro, 2005).

Dentro da cadeia produtiva do frango de corte há três elos concentrados e com poder relativamente grande de fixação de preços: os avozeiros, os frigoríficos e os supermercados. O setor de rações não só deixou de fazer parte dessa "elite" como foi em parte incorporado pelos frigoríficos e criadores independentes. Os setores da criação, produção de milho e soja e os consumidores finais do frango e do ovo têm reduzido poder de negociação de preço, embora o sucesso de cada elo da cadeia dependa de que o fluxo produtivo total não sofra sobressaltos (Martins, 1999).

\section{Cadeia da carne suína}

A cadeia produtiva de carne suína no Brasil apresenta um dos melhores desempenhos econômicos no cenário internacional. As bases desse desempenho são as estratégias empresariais e os avanços tecnológicos e organizacionais incorporados ao longo das duas últimas décadas. Na produção primária vêm ocorrendo mudanças estruturais com aumento de escala, especialização e tecnificação, tendências relacionadas à crescente integração com a estrutura industrial de abate e processamento, e contribuindo assim para o crescimento do rebanho e aumento da produtividade (Miele, 2007, Barcellos, 2008). Quanto ao aspecto tecnológico, a produção é dividida em suinocultura industrial e de subsistência. Constitui a suinocultura industrial os produtores tecnificados (integrados ou independentes), ou seja, aqueles que incorporaram na produção os avanços tecnológicos em genética, sanidade, nutrição, manejo e etc. A suinocultura de subsistência é formada pelos produtores que estão à margem destes avanços tecnológicos, produzem para o auto-consumo e comercializam os excedentes.

A integração da produção através de contratos ou programas de fomento é a forma mais difundida de coordenação da transação entre suinocultores e agroindústrias de abate e processamento nos principais países produtores de carne suína, inclusive no Brasil, e sua participação e importância vêm crescendo nas duas últimas décadas (Miele, 2007).

Dentro do SAG da carne suína, as agroindústrias representam os principais agentes, determinando a estrutura dos agentes à montante (produtores rurais, indústria de insumos) e possuindo grande poder de barganha com elos à jusante (atacado, varejo). Além de atuarem na fase de transformação dos alimentos, as agroindústrias exercem papéis importantes em outros pontos da estrutura do sistema, atuando desde o fornecimento de insumos a produtores até a comercialização do produto final (Eckhardt et al., 2008).

No Brasil a maior parte da produção é realizada nos moldes do sistema de integração, sendo as grandes integradoras empresas como Sadia, Perdigão, Aurora, Alibem, Seara, entre outras. Trata-se de uma cadeia produtiva bem organizada, com boa coordenação das agroindústrias, que têm cada vez mais se desenvolvido, equiparando-se às dos países desenvolvidos.

\section{Competitividade entre as cadeias}

Há vários conceitos de competitividade na literatura, sendo de difícil eleição a definição de um significado que satisfaça toda e qualquer análise mercadológica, assim como os fatores que influenciam a competitividade. É necessário fazer uma distinção sobre o ambiente a ser estudado, pois como Pigatto (2001) coloca, a maioria dos estudos tem dado ênfase à competitividade entre nações, apesar de terem como pano de fundo a competitividade entre firmas ou entre setores. $\mathrm{Na}$ Tabela 1 há alguns conceitos de competitividade e seus fatores determinantes.

Segundo Batalha \& Silva (2007) a competitividade de um setor ou nação seria a soma da competitividade dos agentes (firmas) que o compõem. No caso dos agronegócios, a cadeia agroindustrial é um espaço de 
Tabela 1 - Conceitos de competitividade e seus fatores determinantes

\begin{tabular}{|c|c|c|}
\hline Autor & Definição de competitividade & Fatores determinantes \\
\hline Ferraz et al. (1996) & $\begin{array}{l}\text { a capacidade de a empresa formular e } \\
\text { implementar estratégias concorrências que lhe } \\
\text { permitam ampliar ou conservar, de forma duradoura, } \\
\text { uma posição sustentável no mercado }\end{array}$ & $\begin{array}{l}\text { - fatores empresariais } \\
\text { - fatores estruturais } \\
\text { - fatores sistêmicos }\end{array}$ \\
\hline Coutinho \& Ferraz (1993) & $\begin{array}{l}\text { competitividade pode ser vista como a produtividade } \\
\text { das empresas ligada à capacidade dos governos, } \\
\text { ao comportamento da sociedade e aos recursos } \\
\text { naturais e construídos, e aferida por indicadores } \\
\text { nacionais e internacionais, permitindo conquistar } \\
\text { e assegurar fatias do mercado }\end{array}$ & $\begin{array}{l}\text { - internos à empresa } \\
\text { - fatores setoriais } \\
\text { - fatores sistêmicos }\end{array}$ \\
\hline $\begin{array}{l}\text { Harrison \& Kennedy } \\
\text { (1997 e 1998) }\end{array}$ & $\begin{array}{l}\text { a habilidade para criar e agregar valor a preços iguais } \\
\text { ou menores que outros vendedores } \\
\text { em um mercado específico }\end{array}$ & $\begin{array}{l}\text { - tecnologia } \\
\text { - custos e condições de } \\
\text { obtenção de insumos } \\
\text { - grau de diferenciação } \\
\text { - economias (escala e escopo) } \\
\text { - fatores externos }\end{array}$ \\
\hline Van Duren et al. (1991) & $\begin{array}{l}\text { Competitividade é a habilidade sustentada de } \\
\text { obter lucros e manter market-share nos } \\
\text { mercados interno e externo }\end{array}$ & $\begin{array}{l}\text { - fatores controláveis pela firma } \\
\text { - fatores controláveis pelo } \\
\text { governo } \\
\text { - fatores quase-controláveis } \\
\text { - fatores não controláveis }\end{array}$ \\
\hline
\end{tabular}

Fonte: Pigatto, 2001.

análise diferente dos convencionalmente admitidos em estudos de competitividade. Neste caso a cadeia de produção agroindustrial não pode ser vista como a simples soma da competitividade individual de seus agentes, pois existem ganhos de coordenação, normalmente revelados em arranjos contratuais especialmente adequados às condições dos vários mercados que articulam esta cadeia, que devem ser considerados na análise de competitividade do conjunto do sistema.

A economia mundial vem sofrendo grandes transformações nos últimos anos. A competição entre as empresas tem aumentado nos mais diversos segmentos. As ações conjuntas dentro de uma cadeia produtiva passam a ser cada vez mais fundamentais como forma de sobrevivência. Além disso, a busca constante de satisfação do cliente propiciou o momento para a concretização das alianças mercadológicas, com possibilidade de ganhos maiores para todos os segmentos envolvidos (Carvalho-Rocha, 2001).

Nesse contexto, são competitivas as firmas agroindustriais que conseguem estabelecer vantagens competitivas sustentáveis, por meio de sistemas produtivos de alta performance. Em outras palavras, a competitividade de uma firma pode ser avaliada pela capacidade de ganhar e preservar parcelas de mercado. Para tal, faz-se necessário maximizar as economias de escala (operar no nível mínimo do custo médio), de escopo (combinar na mesma planta produtiva mais de um produto e/ou serviço) e de transação (redução dos custos de negociação) (Faveret \& Siffert, 1998).

No Brasil e no mundo as carnes mais consumidas são as de bovinos, suínos e frango; logo, as cadeias agroindustriais destas carnes competem diretamente entre si, tentando conquistar uma parcela cada vez maior do mercado. A Figura 1 mostra a evolução do consumo de carnes no Brasil.

Apesar de ser a carne mais consumida no mundo, com cerca de $39 \%$ do consumo total de carnes (Saab \& Cláudio, 2009), a carne suína figura apenas em terceiro lugar nesse consumo no Brasil. De acordo com um estudo feito por Universidades do mundo todo, inclusive do Brasil (Neves et al., 2008), coordenado pela Universidade de Copenhagen e financiado pela União Europeia, as principais razões pelas quais o consumo de carne suína no Brasil não decola são culturais, já que o brasileiro ainda vê a produção de carne 


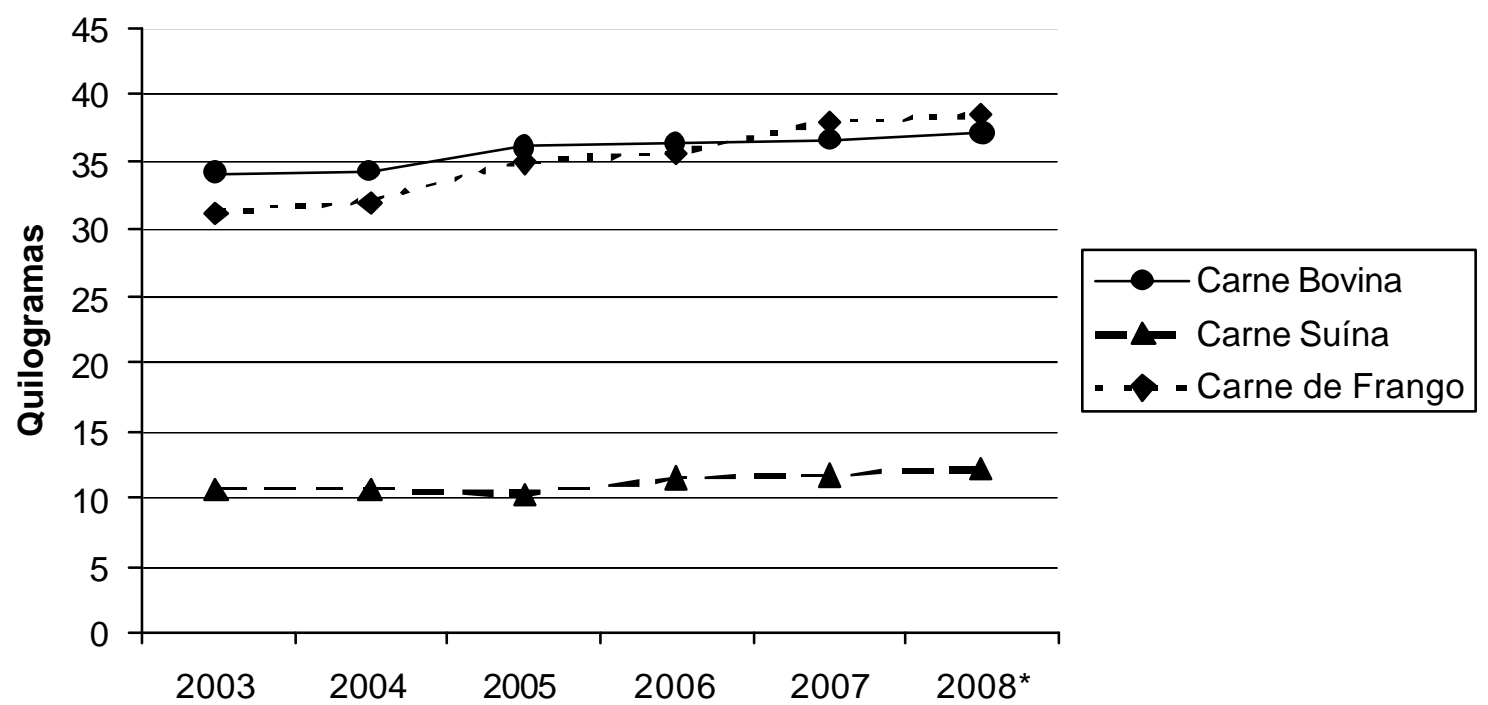

Figura 1 - Consumo de carnes no Brasil (kg/pessoa/ano).

Fonte: Dados USDA * Dados Preliminares

suína como uma atividade suja, na qual um animal extremamente gorduroso é alimentado com restos de comida (Miele, 2007). E desse baixo consumo (cerca de $13 \mathrm{~kg} / \mathrm{hab} /$ ano), aproximadamente $65 \%$ são consumidos na forma de produtos industrializados e embutidos, como presuntos, salsichas, lingüiças, entre outros (Roppa, 2005).

Tradicionalmente a carne mais consumida no Brasil, a partir 2007 a carne bovina teve seu consumo ultrapassado pela carne de frango pela primeira vez na história. Isto se deve não apenas à capacidade da cadeia de frango de baixar seus custos e, consequentemente, o preço final do produto, mas, especialmente, à sua adequação às mudanças nos hábitos e preferências do consumidor final, no sentido de oferecer-lhe maior variedade de opções, enquanto a carne bovina, apenas recentemente, passou a ser oferecida em cortes diferenciados em alguns pontos de venda.

Quanto à produção, pode-se perceber pela Figura 2 que nos últimos anos a produção dos três tipos de carnes tem percorrido trajetórias um tanto diferentes. Ainda que a carne suína apresente a menor produção, bastante inferior aos níveis das demais, ela tem mantido uma trajetória de crescimento constante, com poucas variações. Oexpressivo crescimento do Brasil no cenário internacional da carne suína é reflexo do aperfeiçoamento de toda cadeia produtiva, com a devida adequação frente aos países consumidores e a conquista gradativa de mais mercados.

A concentração da produção interna de carne suína está situada na região sul do país, representante da maior

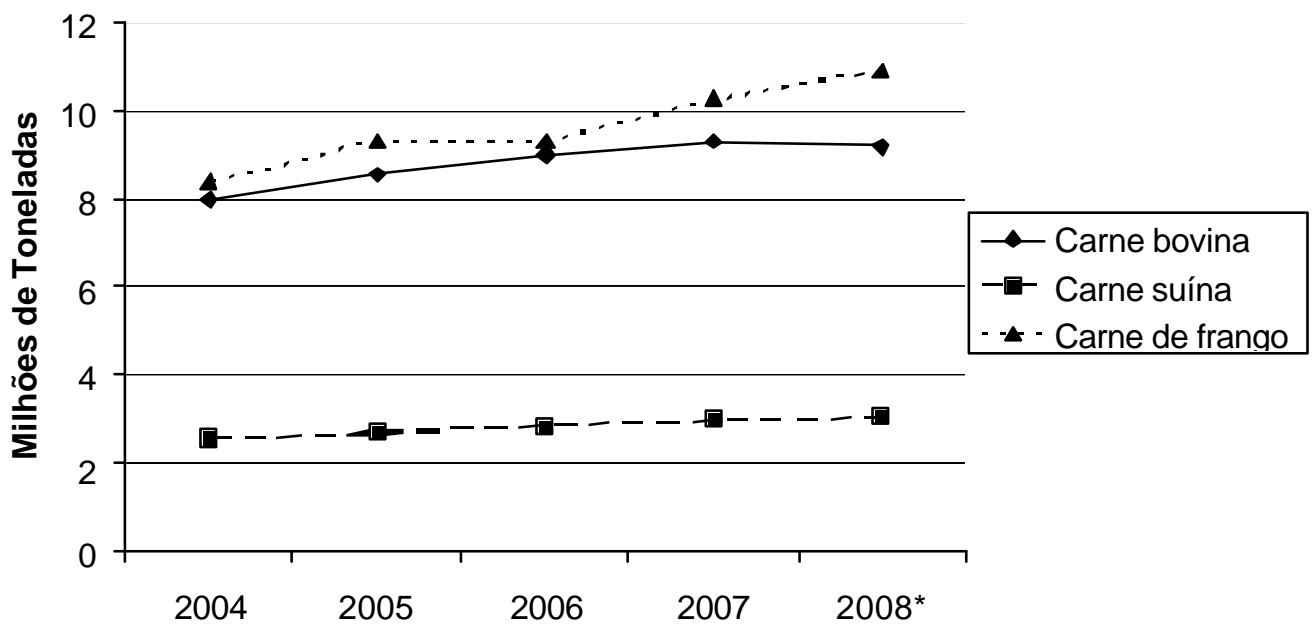

Figura 2 - Produção de carnes no Brasil (equivalente-carcaça). 
parte da produção brasileira. Santa Catarina lidera com aproximadamente $25,6 \%$ do total de carne produzida, seguida pelo Rio Grande do Sul com 16,3\% e Paraná com 14,8\%. Todavia, recentemente, temos observado a difusão da produção para a região centro-oeste do país, fato provavelmente explicado pela maior oferta de milho e soja, propriedades com maior área, melhor utilização de dejetos e maior eficiência logística, contrastando com a saturação do sistema de integração na região sul.

Um fator bastante positivo para a suinocultura brasileira é que a produção industrial tem crescido enquanto que a de subsistência vem caindo constantemente. Isso demonstra o uso cada vez maior de tecnologias de produção, maior profissionalismo no setor e maiores preocupações com a qualidade do produto em toda a cadeia, o que é condição absolutamente necessária para que se obtenha um produto final com garantia de qualidade e segurança alimentar. Enquanto o setor industrial cresceu à taxa de 9,4\% no período de 2002 a 2007 , o setor de subsistência recuou em 41,4\% no mesmo período, sendo responsável em 2007 por apenas $10 \%$ da produção no país (Saab \& Cláudio, 2009).

Já a carne de frango tem tido constantes aumentos de produção devido à sua boa posição nos mercados interno e externo. O consumo interno só vem aumentando e as exportações também. Isso tem impulsionado a produção para cima.

A carne bovina, por sua vez, vem enfrentando uma séria queda no tamanho do rebanho, devido ao elevado abate de matrizes ocorrido nos últimos anos e intensificado a partir de 2005, quando a ocorrência de surtos de febre aftosa no país reduziu significativamente as exportações, aumentando os prejuízos dos pecuaristas. O rebanho ainda não foi recomposto, o que se esperava que ocorresse em 2009. Porém, a crise financeira mundial iniciada em 2008 fez com que essas previsões fossem alteradas. A falta de crédito que afetou todo o setor fez com que se investisse menos em tecnologia, o que reduziu a produtividade do rebanho e, portanto, a velocidade da sua recuperação, que deverá ocorrer apenas nos próximos anos.

Exemplos de diferentes formas de coordenação

\section{Bovinos}

\section{Programa Carne Angus Certificada}

O Programa Carne Angus Certificada é uma parceria entre a Associação Brasileira de Angus (ABA) e a indústria frigorífica, para produção de carne de alta qualidade. O programa tem por objetivos a valorização da carne de animais Angus e suas cruzas, buscar a valorização e o pagamento por qualidade aos produtores engajados, fomentar o crescimento da Raça Angus, fortalecer e integrar a cadeia produtiva além da produção de carne de alta qualidade de acordo com critérios valorizados pelo mercado, com a certificação da ABA, buscando atender os mais exigentes consumidores (www.carneangus.org.br).

Macedo (2009) relata que a condução do programa foi iniciada através de acordo com o Frigorífico Mercosul no Rio Grande do Sul, em 2003, e estabelece padrões de classificação de carcaças com critérios de premiação ao produtor. Em 2007, foi estabelecido acordo com o Frigorífico Marfrig, de Promissão (SP), para a extensão do programa aos produtores localizados no noroeste do estado do Paraná, São Paulo e Mato Grosso do Sul, com padrões específicos de classificação e premiação de carcaças abatidas.

O papel da coordenação é feito pela ABA, que coloca veterinários contratados e treinados para verificar o gado abatido e certificar a carne. Participam ainda do Programa a rede de supermercados Zaffari, o restaurante Barranco, de Porto Alegre (RS), e a butique de carnes VPJ Beef, completando assim todos os elos da cadeia, desde o produtor até o varejo, que tem o contato direto com o consumidor final.

\section{Montana Grill Premium Beef}

A Montana Grill Premium Beef é um projeto que teve início em 2001 pela parceria entre o empresário Ari Nedeff, proprietário das redes de churrascarias Novilho de Prata, Pampeana e Boi Brasil com a dupla de cantores Chitãozinho e Xororó, sob a assessoria técnica do Fundo de Desenvolvimento da Pecuária (FUNDEPEC), que busca comercializar cortes de carne de novilhos de qualidade.

A aliança busca estimular produtores de novilhos (até 04 dentes), através de programa de classificação de carcaças, para a oferta de animais que são abatidos pelo Frigorífico Marfrig, nas unidades de Bataguassu (MS) e Promissão (SP), sob a inspeção de qualidade de técnicos da indústria.

O projeto foi criado com o intuito de congregar um grupo seleto de produtores da raça Montana para a verticalização da produção desde a cria, recria e engorda dos animais, passando pela parceria com o Frigorífico Marfrig, até o varejo, com a formação de uma rede de churrascarias e defastfood, operadas mediante franquias, com fornecimento próprio das carnes comercializadas. Além disso, constituiu-se a marca Montana Premium Beef para a comercialização de cortes especiais embalados através das redes Pão de Açúcar e Zaffari (Macedo, 2009). 
Programa de Carne de Qualidade do Grupo Pão de Açúcar

O programa de Produção de Carne de Qualidade do grupo Pão de Açúcar foi desenvolvido em 2005 com o intuito de atender ao paladar brasileiro e que atendesse às exigências por garantia de qualidade, sustentabilidade ambiental e responsabilidade social.

O programa determina que os animais sejam produzidos a partir do cruzamento de matrizes da raça Nelore com sêmen da raça continental Rubia Galega. Os animais devem ser terminados em semi-confinamento e serem, abatidos com a idade entre 12 e 20 meses e peso vivo entre 420 e $490 \mathrm{~kg}$.

A relação comercial é direta entre a rede de supermercados Extra, pertencente ao grupo Pão de Açúcar, e os produtores, mediante contrato com prazo indeterminado de fornecimento. O volume de abates semanal é de cerca de 300 animais por semana, o frigorífico Marfrig realiza o abate e a desossa dos animais, de acordo com as exigências do grupo Pão de Açúcar, e não possui a responsabilidade de arcar com os custos dos animais.

Suínos

\section{Coordenação pela indústria}

No setor de suínos, predomina um padrão de investimentos que se estende da distribuição à produção de insumos (em granjas núcleo para produção da genética ou em fábricas de ração para a nutrição dos animais), com os estabelecimentos suinícolas inseridos geralmente através de programas de fomento pecuário e de contratos (Miele, 2007). Essa forma de coordenação da atividade pecuária é denominada de integração. "Neste sistema, as agroindústrias fornecem a seus integrados a ração, a genética, os medicamentos, a assistência técnica e outras especificações técnicas, cabendo ao suinocultor os investimentos e manutenção em instalações, a mão-de-obra e despesas com energia, água e manejo dos dejetos. Enquanto que entre as empresas integradoras há uma relação direta com os suinocultores integrados, entre as cooperativas centrais que abatem suínos e processam carne suína essa relação se dá, geralmente, através de cooperativas singulares de produção pecuária. Além da integração, há o chamado mercado spot, no qual as agroindústrias compram animais de estabelecimentos suinícolas denominados independentes, ou seja, que têm liberdade de decisão quanto aos insumos a serem adquiridos ou volume e destino das vendas da produção suinícola. Nesse sistema, verifica-se a existência de comerciantes que adquirem os animais para posterior venda às agroindústrias, com ou sem engorda. Nota-se que em alguns estados, como Santa
Catarina e Rio Grande do Sul, muitos desses comerciantes passaram a fornecer insumos e assistência técnica a outros suin ocultores em troca de garantias tácitas de fornecimento, constituindo-se em um fenômeno denominado no setor como mini-integradores" (Miele, 2007).

Como já citado anteriormente, as indústrias possuem grande poder de coordenação sobre o SAG, inclusive sobre o aspecto do fluxo de informações entre agentes. "O sistema de preços é tradicionalmente utilizado para se averiguar a aceitação de produtos por parte dos consumidores, sendo estes sinais transmitidos aos produtores pelas agroindústrias através de padrões de qualidade exigidos e classificação do material fornecido (grades). Porém, tal mecanismo de transmissão de exigências do consumidor pode falhar ao mesmo tempo em que pode impedir o ideal funcionamento da indústria, já que a busca por matéria prima padronizadaé custosa e pode ser infrutífera" (Eckhardt et al., 2008).

Trata-se, portanto, de uma importante estratégia de concorrência utilizada pelas agroindústrias do SAG da carne suína: a diferenciação, ou seja, a busca por tornar os produtos de uma empresa diferentes dos de seus concorrentes na mente do consumidor. "A criação de uma imagem sólida, expressa por uma marca, junto ao consumidor fortalece a empresa na medida em que reduz o grau de substituição de seus produtos, já que estes estão associados a características ou experiências sensoriais superiores às demais disponíveis no momento da compra. Esta estratégia altera os padrões de concorrência, tirando o foco das estratégias de liderança de custos e menor preço, as quais caracterizam os mercados de commodities, permitindo maiores margens de lucro" (Eckhard et al., 2008).

\section{Um novo olhar sobre a carne suína}

Lançada em 2005 pela ABCS (Associação Brasileira dos Criadores de Suínos), a campanha "Um Novo Olhar Sobre a Carne Suína" mostra, por meio de pesquisas de algumas das principais universidades do país, os valores nutricionais da carne suína. Diferente do que muitos pensam, um bife de determinados cortes suínos pode ter menos colesterol do que um bife de boi ou frango, por exemplo.

O objetivo da campanha é mostrar para a população que comer carne suína é saudável e assim, aumentar as vendas. Em uma pesquisa realizada em 2004, 49\% dos brasileiros responderam que preferem o sabor da carne suína a outras carnes. No entanto, não a consome por fatores como preconceito, preço, conveniência, formato e associação com a obesidade. O desafio então é estimular o consumo através de campanhas de marketing, além de reestruturar a forma como o produto é comercializado no Brasil. 
Hoje a carne de porco é encontrada também em porções menores, pré-pronta, acondicionada de forma mais atraente e com novos cortes, como strogonoff, medalhões de mignon, escalopinhos de alcatra e carne moída premium sem resíduo de gordura.

O projeto piloto foi lançado no Mato Grosso, Minas Gerais, Rio Grande do Sul, São Paulo e no Distrito Federal, envolvendo frigoríficos e varejistas locais, com a realização de cursos e palestras, além da degustação do produto nos pontos de venda.

Apesar de ser basicamente uma campanha de marketing, a sua realização envolve uma série de transações marcadas por especificidades temporais e locacionais, e a participação comprometida dos agentes envolvidos, o que gera a necessidade de uma rígida coordenação em termos de garantia de qualidade e disponibilização do produto final. Aves

Entre os sistemas contratuais de coordenação da cadeia do frango, citamos o sistema de parceria da Seara Alimentos S.A., que ocorre, segundo Grunow (2006), da seguinte maneira: a Seara Alimentos S.A. fornece os pintinhos de um dia, ração, assistência técnica e transporte. Ficam sob responsabilidade dos parceiros a aquisição de maravalha, gastos relacionados com a criação e o carregamento das aves vivas, tais como mão-de-obra para o trato, limpeza e desinfecção, controle integrado de pragas, energia elétrica, água, gás ou lenhas e, quando aplicável, a utilização de desinfetantes e medicamentos recomendados pela Seara Alimentos S.A.

É de responsabilidade da equipe técnica da Seara Alimentos S.A. a orientação aos parceiros quanto à criação das aves, tanto no que diz respeito às instalações, manejos, condições sanitárias e meio ambiente.

Quando os animais chegam na plataforma de abate é realizada a avaliação das aves de corte, no abatedouro, quanto a alguns itens sanitários, com a finalidade de identificar a qualidade das aves, buscando-se melhorar continuamente o chamado FEP (Fator de Eficiência de Produção). A cada fechamento de lote é analisado pelo gestor do processo o desempenho dos parceiros através dos indicadores de desempenho de peso, conversão alimentar e mortalidade.

\section{Aves e Suínos}

As cooperativas são um grande exemplo de coordenação de SAGs. Entre elas, destaca-se a Coopercentral Aurora. Com sede em Chapecó, a Aurora reúne 16 cooperativas singulares que, no conjunto, representam cerca de 72 mil produtores rurais. Com um mix de 700 produtos, entre carnes de aves e suínos, lácteos e pizzas, a Coopercentral Aurora registra crescente participação no mercado nacional.

A Aurora nasceu, em 1969, da reunião de oito cooperativas de produção agrícola (hoje são 16) que perceberam a importância estratégica da conjugação de esforços para superar a condição de fornecedor de matériaprima a que estavam destinados os produtores rurais. Ao organizar a produção em nível regional e obter uma oferta em escala, a Coopercentral Aurora criou as bases para a industrialização da produção gerada pelos associados das cooperativas singulares filiadas e permitiram construir uma estrutura agroindustrial capaz de absorver, transformar e conquistar mercado para essa produção.

Hoje processa matéria-prima gerada por mais de 72.000 famílias rurais associadas às 16 cooperativas filiadas à Coopercentral, garantindo renda e mercado. No plano externo, tornou-se uma empresa do setor de alimentos e não mais, apenas, de produtos cárneos, com marcante inserção nacional e crescente participação no comércio internacional. Essa nova visão foi formatada no atual planejamento estratégico da cooperativa e manifestou-se, concretamente, com a diversificação de seu mix de produção e o lançamento da linha de lácteos e pizzas, entre outras ações.

No segmento de suínos, em 2008 o abate cresceu 4,7\% e atingiu 3.223 mil cabeças. A produção in natura (274,8 mil toneladas) e a industrialização de carne suína (243,5 mil toneladas) permaneceram estáveis em relação ao ano anterior. A empresa implantou o projeto "Suíno ideal" para estabelecer uma padronização definitiva e fornecer aos abatedouros carcaças com características ideais para melhor aproveitamento industrial.

No segmento de aves, foram abatidos no mesmo ano 119.979 mil frangos, com incremento de $6,67 \%$ em relação a 2007. A produção in natura de carne de frango cresceu $8,4 \%$ e atingiu 228,2 mil toneladas. A industrialização de aves evoluiu $57 \%$, para 36 mil toneladas.

\section{Análises e Implicações}

Ao se destacar as diferentes formas de coordenação existentes nos SAGs das carnes bovina, suína e de frango, há que se atentar para as grandes diferenças existentes entre os sistemas produtivos. Existe produção de bovinos em todo o Brasil, o que não acontece com suínos e aves, pelo menos não em escala industrial. Isso dificulta enormemente a difusão de tecnologias. Há enorme variedade de raças e sistemas de produção, resultando em produtos bastante diferentes entre si. O fator tempo também é extremamente importante nesta comparação, já que um frango ou um suíno têm ciclos de vida imensamente 
menores que suínos e frangos, possibilitando pesquisas e avanços genéticos muito mais rápidos e eficazes.

No setor industrial também existem grandes diferenças, uma vez que os segmentos de carnes de frango e suína são caracterizados pela existência de grandes indústrias, que fazem elas próprias a coordenação de suas cadeias. O segmento de abate e industrialização de bovinos, apesar da grande concentração ocorrida recentemente, ainda é bastante pulverizado e disperso geograficamente.

Assim, ao se comparar as cadeias em termos de competitividade percebe-se que, independentemente de quem as coordene, seja uma empresa, associação de produtores ou cooperativa, é importante que se tenha a noção da realização de ações visando o bem comum, e que a coordenação funcione de forma a garantir a qualidade de produtos diferenciados e ao mesmo tempo trazer uma justa remuneração aos participantes da cadeia, especialmente o produtor, que em geral não é remunerado por atributos de qualidade do seu animal. As alianças e contratos, formais ou informais, em geral garantem que os investimentos realizados no sentido de buscar uma qualidade superior do animal valham a pena em termos de retorno financeiro. Eles exigem que se tenha bem definidos os atributos desejados entre as partes, e isto é informado ao consumidor final, já que é parte importante das alianças que se faça uma comunicação clara ao consumidor de que se trata de um produto diferenciado por uma marca, uma raça ou outro diferencial que exista. Só assim será possível a precificação do produto de maneira a tornar possível também que se remunere de acordo. No entanto, a partir do momento em que se promete um nível específico de qualidade ou de qualquer outro atributo ao consumidor (no caso da carne, pode ser maciez, sabor, procedência, raça ou idade do animal, forma de abate, forma de manejo do animal, presença ou ausência de resíduos, medicamentos, entre muitos outros), todos na cadeia tornam-se comprometidos com a presença desses atributos no produto final. E a maior dificuldade pode estar justamente na confiabilidade dos elos da cadeia a respeito do fiel comprometimento no fornecimento do produto dentro dos padrões exigidos pela aliança. Cada um dos participantes da aliança, acordo, parceria ou contrato, nos diversos níveis da cadeia, tem que se comprometer em entregar o produto, no caso a carne, nas quantidades e dentro dos padrões inicialmente acordados. O pecuarista, por exemplo, não pode mais olhar para o mercado e vender a quem estiver pagando melhor. A indústria idem. Não pode resolver, no meio do processo, vender o produto que seria destinado à aliança a outro cliente e tentar substituir o produto por outro de qualidade diferente, independente de ser superior, inferior ou de padrão semelhante ao acordado. A partir do momento que a aliança estiver formada, todos os agentes passam a estar comprometidos com a manutenção do padrão e da disponibilização do produto nas quantidades e prazos acordados. É aí que estarão os ganhos de competitividade da cadeia e de cada agente participante.

\section{Literatura Citada}

ALVES, M.R.P.A. Logística agroindustrial. In: BATALHA, M.O. (Ed.) Gestão agroindustrial. 1.ed. São Paulo: Atlas, 1997.

BATALHA, M.O.; SILVA, A.L. Gerenciamento de sistemas agroindustriais. In: BATALHA, M.O. (Ed.) Gestão agroindustrial. 3.ed. São Paulo: Atlas, 2007. p.1-64.

BORRÁS, M.A.A.; TOLEDO, J.C. A coordenação de cadeias agroindustriais In: ZUIN, F.S.; QUEIROZ, T.R. (Eds.) Agronegócios gestão e inovação. 1.ed. São Paulo: Saraiva, 2006. p.23-50.

CARVALHO-ROCHA, J.C.M.; FAVA NEVES, M.; LÔBO, R.B. Experiências com alianças verticais na coordenação da cadeia produtiva da carne bovina no Brasil. In: CONGRESSO INTERNACIONAL DE ECONOMIA E GESTÃO DE NEGÓCIOS, 3., 2001, Ribeirão Preto. Anais... Ribeirão Preto: FEA-USP, 2001.

CASTRO, W.L.; AStUti, E.L.; BOTELHO, F.B. Arranjos contratuais entre diferentes elos da cadeia avícola no Distrito Federal. Brasília: 2005.

ECKHARDT, O.H.O. et al. [2009]. Iniciativas do sistema agroindustrial da carne suína para sinalizar excelência Disponível em: <http://www.porkworld.com.br.> Acesso em: $15 / 4 / 2009$.

FAVERET FILHO, P.; SIFFERT FILHO N. O sistema agroindustrial de carnes: competitividade e estruturas de governança. In: SEMINÁRIO SOBRE COMPETITIVIDADE NA INDÚSTRIA DE ALIMENTOS, 1998, Campinas.

JANK, M.S. Competitividade do agribusiness brasileiro: discussão teórica e evidências no sistema carnes. 1996. Tese de Doutorado (Administração) - Faculdade de Economia, Administração e Contabilidade, Universidade de São Paulo, São Paulo, 1996.

MACEDO, L.O.B. Perfil de governança e a coordenação de alianças estratégicas do sistema agroindustrial da carne bovina brasileira. 2009. 203f. Tese (Doutorado) - Escola Superior de Agricultura "Luiz de Queiroz"/Universisdade de São Paulo, Piracicaba, 2009.

MARTINS, S.S. Mecanismos de coordenação nas cadeias produtivas do frango e do ovo. Informações Econômicas, v.29, n.6, p.23-33, 1999.

MORAES, M.A.F.D.; MACEDO, L.O.B. Perfil de governança e a coordenação de alianças estratégicas do sistema agroindustrial da carne bovina brasileira. Informações Econômicas, v.39, n.3, 2009.

NEVES, M. F. et al. Q-Pork Chains: Improving the quality of pork and pork products for the consumer. Development of innovative, integrated, and sustainable food production chains of high quality pork products matching consumer demands. Deliverable D.1.1.2 Pork Consumption in Europe and Beyond: Comprehensive Report. Part B: Pork Consumption in Brazil. Internal Document, 2008.

PIGATTO, G.; SILVA, A.L.; SOUZA FILHO, H.M. Alianças mercadológicas: a busca da coordenação na cadeia de gado de 
corte brasileira. In: WORKSHOP BRASILEIRO DE GESTÃO DE SISTEMAS AGROALIMENTARES, 2., 1999, Ribeirão Preto. Anais... Ribeirão Preto: 1999.

ROPPA, L. Suinocultura mundial: situação atual e perspectivas. Pork World, v.4, n.25, 2005.

SAAB, M.S.B.L.M. Valor percebido pelo consumidor - um estudo de atributos da carne bovina. 1999. Dissertação de Mestrado - FEA/USP. Departamento de Administração, São Paulo, 1999.

SAAB, M.S.M.; CLÁUDIO, L. D. G., A cadeia produtiva da carne suína no Brasil. Pork World, v.8, n.49, 2009.

SAAB, M.S.M.; NEVES, M.F. Pork chain in Brazil and Canada: a comparison. In: TRIENEKENS, J. et al. European pork chains
- Diversity and quality challenges in consumer-oriented production and distribution. Wageningen, The Netherlands: Wageningen Academic Publishers, 2009. p.245-255.

TRIENEKENS, J.; WOGNUN, N. Introduction to the European pork chain. In: TRIENEKENS, J. et al. (Eds.) European pork chains - Diversity and quality challenges in consumer-oriented production and distribution. Wageningen: The Netherlands: Wageningen Academic Publishers, 2009. p.19-36.

ZYLBERSZTAJN, D. Estruturas de governança e coordenação do agribusiness: uma aplicação da nova economia das instituições. 1995. Tese (Livre-docência), Departamento de Administração, FEA/USP, São Paulo, 1995. 